\title{
Pubertal breast development in primary school girls in Sokoto, North-Western Nigeria
}

M O Ugege, ${ }^{1}$ MBBS, FWACP, FESPE; K I Airede, ${ }^{2} \mathrm{MBBS}, \mathrm{MPH}, \mathrm{FWACP}$; A Omar, ${ }^{3} \mathrm{MD}$, MMed (Paed), FPE;

O Pinhas-Hamiel, ${ }^{4} \mathrm{MD}$; P K Ibitoye, ${ }^{1} \mathrm{MBBS}$, FWACP; U Chikani, ${ }^{5} \mathrm{MBBS}$, FMCPaed, FESPE; A Adamu, ${ }^{1} \mathrm{MBBS}, \mathrm{FWACP}$; K O Isezuo, ${ }^{1}$ MBBS, FWACP; F Jiya-Bello, ${ }^{1}$ MBBS, FMCPaed; J A Legbo, ${ }^{1}$ MBBS; M Sanni, ${ }^{1}$ MBBS

\author{
${ }^{1}$ Department of Paediatrics, Usmanu Danfodiyo University Teaching Hospital, Sokoto, Nigeria \\ ${ }^{2}$ Faculty of Clinical Sciences, University of Abuja, Federal Capital Territory, Abuja, Nigeria \\ ${ }^{3}$ Kenyatta National Hospital, Nairobi, Kenya \\ ${ }^{4}$ Paediatric Endocrine and Diabetics Unit, Edmund and Lily Safra Children's Hospital, Sheba Medical Center, Sheba, Israel \\ ${ }^{5}$ University of Nigeria Teaching Hospital, Enugu, Nigeria
}

Corresponding author: M O Ugege (shallyben@yahoo.com)

\begin{abstract}
Background. There is wide variation in normal pubertal timing among various populations.
Objectives. To determine the mean age of pubertal stages of breast development and menarche, and the influence of nutrition and ethnicity on pubertal onset in primary school girls in Sokoto, North-Western Nigeria.

Methods. A cross-sectional study using a multistage random sampling design was conducted on 994 primary school girls in grades 3 - 6 . Weight and height measurements and Tanner breast staging were done. Body mass index (BMI) was calculated, and a BMI-for-age percentile was used to categorise nutritional status. There were four major ethnic groups. $P \leq 0.05$ was taken as showing statistical significance.

Results. The participants' mean age was 10.23 years (standard deviation (SD) 1.70, range 6 - 15 years). Of the 994 girls, 628 (63.2\%) were pre-pubertal, and $366(36.8 \%)$ were pubertal. Of the latter, $158(15.9 \%)$ were in breast stage 2, while $112(11.3 \%), 70(7.0 \%)$ and $26(2.6 \%)$ were in breast stages 3,4 and 5, respectively. The mean ages (SD; range) of pubertal onset and menarche were 10.50 (1.33; 8 - 13), and $12.67(1.65 ; 11$ - 15), years, respectively. The overnourished (overweight/obese) and Igbo ethnic group girls had early-normal pubertal onset ( $p=0.006$ and $p=0.001$, respectively).

Conclusion. The mean ages of Tanner breast stages $1-5$ and menarcheal age of girls in Sokoto, North-Western Nigeria, were within the age ranges reported worldwide. Pubertal onset was influenced by nutrition.
\end{abstract}

S Afr J Child Health 2017;11(1):33-37. DOI:10.7196/SAJCH.2017.v11i1.1199

Puberty is a period of maturation during which secondary sexual characteristics appear and reproductive capability is attained. Its onset requires an intact hypothalamic-pituitary-gonadal axis, the reactivation of the secretion of pulsatile gonadotrophin-releasing hormone from its stage of childhood quiescence, and the stimulation of luteinising hormone and follicle-stimulating hormone secretion, which in turn activate the production of the gonadal sex steroid, oestradiol, in girls. ${ }^{[1-3]}$

The external sign of puberty onset in girls is the appearance of breast buds, because breast tissue is the primary target of oestradiol. This usually occurs between 10 and 11 years of age. ${ }^{[4]}$ Menarche occurs in middle or late puberty, usually within 2 years of pubertal onset. ${ }^{[2]}$ However, there is wide variation in the normal pubertal timing among various populations separated in time and space. ${ }^{[4,5]}$ Many different factors contribute to this variation, including genetic factors, ${ }^{[2]}$ nutrition, ${ }^{[6,7]}$ ethnicity ${ }^{[8,9]}$ and socioeconomic status. ${ }^{[6,10]}$

Previous studies have shown a decreasing mean age of pubertal breast development over time. ${ }^{[6-11]}$ Most have documented the mean age as being between 8 and 9 years. This has been attributed to the secular trend, defined as the continuous movement of a variable in a somewhat consistent way over a long period of time. The secular trend of puberty therefore refers to a decreasing average age of puberty over time, explained by the decline in frequency and severity of illnesses, and the better health and nutritional status of the general population. ${ }^{[6,12]}$ Studies have shown that obesity and overweight are important contributing factors to the earlier onset of puberty in girls. ${ }^{[3,7,10]}$ Most of these studies were conducted in America, Europe and Asia. The studies conducted on black people were carried out on African Americans. Few studies on pubertal onset have been conducted on African children living in Africa. ${ }^{[13,14]}$ The influence of environment and geographical location on pubertal timing has been previously documented. ${ }^{[15,16]}$ Most Nigerian studies have focused on age at menarche and influencing factors. ${ }^{[17,18]}$ To the best of our knowledge the only similar Nigerian study was conducted on girls (10 - 20 years old) from the Igbo ethnic group. ${ }^{[19]}$

There is a paucity of literature regarding pubertal breast development in the black African population, and utilising normative data from white girls or African Americans may not be truly representative of the Nigerian or African population as a whole. The aim of this study was to determine the mean age of pubertal stages of breast development and menarche, and to determine the influence of nutrition and ethnicity on pubertal onset, in primary school girls living in Sokoto, Nigeria.

\section{Methods \\ Study design}

A cross-sectional study was conducted between December 2014 and March 2015 on primary school girls in grades $3-6$ in both public and private primary schools.

\section{Study location}

The study was carried out in Sokoto, the capital city of Sokoto state, in the North-Western geopolitical zone of Nigeria. Nigeria has more than 250 ethnic groups, but the three major ethnic groups 
are the Hausa-Fulani, Igbo and Yoruba, which together constitute $71 \%$ of the population. ${ }^{[20]}$ In Sokoto most Nigerian ethnic groups are well represented, but the majorities are the indigenous Hausa and Fulani. For the purpose of this study, ethnicity was stratified to five groups: Hausa, Fulani, Igbo, Yoruba and others, which consist of a heterogeneous group of minor tribes found in Nigeria and neighbouring countries. This was in an attempt to reflect genetic background, and the sociocultural practices peculiar to the major ethnic groups in Nigeria, some of which are related to type of diet, nutrition and lifestyle. A cross-section of all socioeconomic classes in the metropolis was well represented.

\section{Ethical approval and parental consent}

The study protocol was approved by the Ethical Committee of the Usmanu Danfodiyo University Teaching Hospital (UDUTH), Sokoto (ref. no. UDUTH/HREC/2014/No 265). Written permission was obtained from the Ministry of Education, and written parental informed consent was obtained from the parents or guardians, as well as assent from all participants.

\section{Recruitment and data collection}

Questionnaires were used to record the subjects' biological and sociodemographic data, including age, ethnicity/tribe (the ethnic group of the father was taken as each subject's ethnic group), the marital status of parents/guardians and their occupations. The age at menarche was obtained by self-report if the subject was postmenarcheal at the time of the interview. Weight was measured to the nearest $0.1 \mathrm{~kg}$ using an electronic portable weighing scale (Omron digital personal scale HN283, Japan). The subjects were dressed in lightweight school uniforms. Height was measured using a portable stadiometer (Prevenar 13 Kidmeter, Pfizer, Spain) to the nearest $0.1 \mathrm{~cm}$. These measurements were taken by properly trained research assistants. Body mass index (BMI) was calculated by dividing the weight in kilograms by the square of the height in metres. Nutritional status was classified using BMI-for-age percentiles according to National Centre for Health Statistics ${ }^{[21]}$ as follows: underweight $<5$ th percentile, normal weight 5 th $-<85$ th percentile, overweight: 85 th $<95$ th percentile, obese: $\geq 95$ th.

\section{Pubertal breast staging}

Pubertal breast staging was assessed by the principal researcher according to the pubertal staging described by Tanner ${ }^{[4]}$ Breast stages 1 - 5 were assessed by inspection, and palpation where necessary, for instance, to properly distinguish a visible breast bud from simple adipose tissue. Where the two breasts of an individual were not at the same stage of development, the stage of the more advanced side was recorded. The onset of puberty was accepted as Tanner breast stage 2 (B2 - appearance of breast bud). In cases of uncertainty between two adjacent stages, the subject was additionally evaluated by a second researcher and a consensus decision was reached.

\section{Statistics}

Power analysis showed that a sample size of 600 girls would have $80 \%$ power to detect a difference of 1 month, assuming that the common standard deviation (SD) is 1 with a 0.05 two-sided significancelevel. ${ }^{[22,23]}$ Multistage random sampling was utilised in the selection of three local government areas (LGAs) out of five, and 20 (30\%) of the total number of schools in the Sokoto metropolis. Both public and private schools were selected in proportion to their distribution in the three LGAs. Consequently, we selected 12 private and 8 public schools. However, only $70 \%$ of the selected schools $(n=14: 8$ private and 6 public) permitted the study ( $21 \%$ of the total number of schools in the metropolis).

All the primary schools were co-educational, and all the girls whose parents consented in grades 3 - 6 were included as a cluster.
The data were processed using the Statistical Package for Social Sciences version 20 (IBM Corp., USA). SD scores (or $z$-scores) were generated from the BMI, and these were converted to BMI percentiles using a $z$-score percentile converter. ${ }^{[24]}$ The BMI percentiles were used to categorise nutritional status. The age at onset of puberty was categorised as precocious ( $<8$ years), normal ( $8-13$ years) or delayed ( $>13$ years). Statistical analysis involved Fisher's exact test, analysis of variance (ANOVA), Student $t$-tests and logistic regression, as appropriate. All statistical analysis was done at a $p \leq 0.05$ level of significance.

\section{Results}

\section{General characteristics of the study population}

The study cohort comprised 994 girls, 506 (51\%) from private schools and 488 (49\%) from public schools. Their mean (SD) age was 10.23 (1.7) years, range 6 - 15 years. Most participants were between the ages of 8 and $<10$ or 10 and $<12$ years $(34.9 \%$ and $39.6 \%$, respectively). The $6-<8$ years group were the minority (4.5\%). The $12-<13$ and $13-15$-year-olds stood at $10.6 \%$ and $10.4 \%$, respectively. Age was unknown in $14(1.4 \%)$ subjects.

\section{Ethnic distribution}

The majority $(n=486 ; 49 \%)$ of the participants were Hausa and a minority $(n=70 ; 7.1 \%)$ were Igbo. Ninety-six $(9.7 \%)$ were Yoruba, $84(8.5 \%)$ were Fulanis, and $256(5.8 \%)$ were classified as 'others', a heterogeneous group consisting of minor tribes from within the six geopolitical zones of Nigeria, and tribes from neighbouring countries such as Niger and Benin Rebublic. Two participants did not know their ethnic group $(0.2 \%)$.

\section{The nutritional status of the study population using BMI-for-age percentiles}

The majority of the subjects $(888(89.3 \%))$ were of normal weight. Only $2(0.2 \%)$ were underweight. There were 40 overweight and 64 obese subjects ( $4 \%$ and $6.4 \%$, respectively).

\section{Biodemographic, anthropometric and pubertal characteristics of the study population}

Table 1 shows the distribution of the study population by age, weight, height and BMI, median BMI-SDs and type of school, categorised according to the Tanner stage and menarche.

The majority $(628(63.2 \%))$ of the study population was prepubertal. Only $366(36.8 \%)$ were pubertal, of whom $158(15.9 \%)$ were in breast stage 2, and $112(11.3 \%), 70(7.0 \%)$ and $26(2.6 \%)$, were in breast stages 3, 4 and 5, respectively. Fourteen (1.4\%) had attained menarche. Mean (SD) age of pubertal onset (B2) was 10.50 (1.33) years. The mean (SD) (age) of menarche was 12.67 (1.65) years. The mean age of Tanner breast stages significantly increased as the stages progressed $(p<0.001)$, except for Tanner 4 . The mean duration from pubertal onset to menarche was 2.17 years. The mean weight, height and BMI of the study population increased with progressing Tanner stage from B1 to B5. This generally observed increase was statistically significant $(p<0.001)$. There were 1.3 times more girls in B2 (pubertal onset), and 2.5 times more post-menarcheal girls in private schools than public schools.

\section{Comparison of mean age of pubertal onset, weight, height and BMI of girls in public and private schools} Table 2 shows the mean age of pubertal onset and menarche, weight, height and BMI of subjects in Tanner stage B2 in private and public schools. The girls in private schools had a lower mean age of pubertal onset than the girls from public schools $(p=0.04)$. Similarly, girls in private schools had a higher mean weight, height and BMI than those in public schools ( $p=0.03,0.001$ and 0.04 , respectively). The age ranges of pubertal onset and menarche of subjects in private schools were 8 - 
Table 1. Distribution of study population by type of school, and the mean age, weight, height, BMI and median BMI-SDS according to the Tanner stage and menarche ${ }^{\star}$

\begin{tabular}{|c|c|c|c|c|c|c|c|c|}
\hline TS & $\begin{array}{l}\text { Pu, } \\
N(\%)\end{array}$ & $\begin{array}{l}\text { Pr, } \\
N(\%)\end{array}$ & $\begin{array}{l}\text { Total, } \\
N(\%) \\
\end{array}$ & $\begin{array}{l}\text { Age (years), } \\
\text { mean (SD) }\end{array}$ & $\begin{array}{l}\text { Weight (kg), } \\
\text { mean (SD) }\end{array}$ & $\begin{array}{l}\text { Height }(\mathrm{cm}) \text {, } \\
\text { mean }(\mathrm{SD})\end{array}$ & $\begin{array}{l}\text { BMI }\left(\mathrm{kg} / \mathrm{m}^{2}\right) \text {, } \\
\text { mean }(\mathrm{SD})\end{array}$ & $\begin{array}{l}\text { BMI-SDS } \\
\text { (median) }\end{array}$ \\
\hline B1 & $310(63.5)$ & $318(62.8)$ & $628(63.2)$ & $9.63(1.47)$ & $26.21(4.93)$ & $131.0(7.05)$ & $15.22(1.87)$ & $-0.2(1.0)$ \\
\hline B2 & 68 (13.9) & $90(17.8)$ & $158(15.9)$ & $10.50(1.33)$ & $31.51(5.44)$ & $138.3(5.68)$ & $16.52(2.82)^{\dagger}$ & $-0.3(1.0)$ \\
\hline B3 & $64(13.1)$ & $48(9.5)$ & $112(11.3)$ & $11.58(1.52)$ & $33.87(6.40)$ & $144.4(7.48)$ & $16.16(1.90)^{\ddagger}$ & $-0.1(1.0)$ \\
\hline B4 & $30(6.1)$ & 40 (7.9) & $70(7.0)$ & $11.58(1.08)$ & $37.50(7.25)$ & $145.7(7.10)$ & $17.59(2.79)$ & $-0.2(1.0)$ \\
\hline B5 & $16(3.3)$ & $10(2.0)$ & $26(2.6)$ & $13.72(1.33)$ & $48.24(5.26)$ & $152.8(4.30)$ & $21.55(3.19)$ & $-0.4(1.0)$ \\
\hline $\mathbf{M}$ & $4(0.82)$ & $10(1.97)$ & $14(1.4)$ & $12.67(1.65)$ & $50.06(6.15)$ & $152.4(4.97)$ & $21.54(2.54)$ & $-0.5(1.0)$ \\
\hline
\end{tabular}

TS = Tanner stage; $\mathrm{M}=$ menarche; $\mathrm{Pu}=$ public school; $\mathrm{Pr}=$ private school; $\mathrm{BMI}-\mathrm{SDS}=$ body mass index standard deviation score

${ }^{\star}$ Age v. TS $p=<0001$; Weight v. TS $p=<0.001$; Height v. TS $p=<0.001$; BMI v. TS $p=<0.001 ;{ }^{\dagger}$ v. ${ }^{\ddagger} p=0.24$.

Table 2. Comparison of mean age of pubertal onset (B2), menarche, weight, height and BMI of subjects in public and private school

\begin{tabular}{|c|c|c|c|c|c|c|c|}
\hline \multirow[b]{2}{*}{ Variable } & \multicolumn{3}{|c|}{ Private school } & \multicolumn{3}{|c|}{ Public school } & \multirow[b]{2}{*}{$p$-value ${ }^{\star}$} \\
\hline & $N$ & Mean (SD) & Range & $N$ & Mean (SD) & Range & \\
\hline Age (years) & 90 & $9.90(1.04)$ & $8.00-13.00$ & $66^{\dagger}$ & $11.11(1.23)$ & $9.00-13.00$ & 0.04 \\
\hline Menarche (years) & 10 & $11.75(0.76)$ & $11.00-12.92$ & 4 & $15.00(0)$ & - & - \\
\hline Weight (kg) & 90 & $32.94(6.46)$ & $25.10-55.30$ & 68 & $29.62(2.74)$ & $23.7-34.9$ & 0.03 \\
\hline Height $(\mathrm{cm})$ & 90 & $138.39(5.95)$ & $125.0-151.5$ & 68 & $138.23(5.28)$ & $128.5-149.5$ & 0.001 \\
\hline BMI $\left(\mathrm{kg} / \mathrm{m}^{2}\right)$ & 90 & $17.31(3.38)$ & $13.80-29.50$ & 68 & $15.49(1.22)$ & $12.83-17.94$ & 0.04 \\
\hline BMI SDS (median) & 90 & $-0.20(1.00)$ & $-1.50-5.10$ & 68 & $-0.20(1.00)$ & $-2.00-6.50$ & - \\
\hline
\end{tabular}

13 and 10 - 15 years, while those of their counterparts in public schools were $9-13$ and $11-15$ years, respectively.

\section{Influence of nutrition on the age of pubertal onset}

A total of 144 (91.1\%), $2(1.3 \%)$ and $12(7.6 \%)$ of the subjects in Tanner B2 were normal weight, overweight and obese, respectively. None was underweight. All the subjects in Tanner B2 were between 8 and 13 years old. To determine the relationship between nutritional status and age at onset of puberty, this age range was further categorised as shown in Table 3, which indicates the influence of nutritional status on the age of pubertal onset. Eighty-six (55.1\%) of girls in Tanner breast stage 2 (B2) were between 8 and 10 years old (early-normal pubertal onset), $54(34.6 \%)$ were $>10$ - 12 years (middle-normal pubertal onset) and $16(10.3 \%)$ were $>12$ - 13 years (late-normal pubertal onset). A little above half $(51.7 \%)$ of the girls with normal weight had earlynormal pubertal onset. All the girls who were overweight or obese had early-normal pubertal onset, even though overweight and obese girls in $\mathrm{B} 2$ constituted the minority of the sample. A statistically significant association was observed between overnutrition (overweight and obesity) and early-normal age of pubertal onset (Fisher's exact $\chi^{2}$ (FE $\left.\chi^{2}\right)=12.057, p=0.006$ ). Logistic regression analysis showed that girls who were overweight or obese were only 1.259 times more likely to have early-normal pubertal onset compared with those of normal weight (odds ratio (OR) 1.259, $p=0.001$ ).

\section{Influence of ethnicity on the age of pubertal onset}

The influence of ethnicity on the age of pubertal onset is shown in Table 4. Analysis involved all participants in B2. All of the Igbos (100\%), $66.7 \%$ of the Yorubas, $50 \%$ of the Fulanis and $36.4 \%$ of the Hausa participants had early-normal pubertal onset. Half $(50 \%)$ of the Fulanis and $45.5 \%$ of the Hausa participants had middle-normal pubertal onset. Only $18.2 \%$ of the Hausa participants had latenormal pubertal onset.

A statistically significant association was observed between the Igbo ethnic group and early-normal age of pubertal onset $\left(\left(\mathrm{FE} \chi^{2}\right)=\right.$
24.184, $p=0.001$ ). However, multinomial regression analysis showed that ethnicity was not a predictor of the age of pubertal onset.

\section{Discussion}

This study has demonstrated mean (SD) age of Tanner breast stages 1 - 5 of 9.63 (1.47), 10.50 (1.33), 11.58 (1.52), 11.58 (1.08), and 13.72 (1.33), respectively. The girls who were in a more advanced Tanner stage of breast development were older. This finding, as in most other studies, was statistically significant, ${ }^{[10,11,23]}$ suggesting a linear relationship between sexual maturity and chronological age in a normal setting.

The mean (SD) age of pubertal onset of 10.50 (1.33) years found in this study is similar to the 10.55 (1.57) reported by Bazrafshan et al. ${ }^{[25]}$ in Northern Iran in 2005, and slightly lower than the 10.71 years reported in Egypt by Hosney et al..$^{[14]}$ in 2000 . However, our finding is higher than the 9.50 but similar to the 10.30 years reported by Wu et al. ${ }^{[9]}$ from a study on African Americans and white Americans, respectively, in the USA in 2002. It is also greater than the 9.13 years reported in Denizli, Turkey in 2005 (Semiz et al.) ${ }^{[6]}$ the 10.10 years reported in all provinces in Iran in 2006 (Rabbani et al.), ${ }^{[26]}$ the 9.86 years reported in Copenhagen in 2008 (Juul et al.), ${ }^{[27]}$ the 9.71 years reported in Qazvin province, Iran in 2010 (Saffariet al.), ${ }^{[11]}$ the 10.10 years reported in urban South Africa (SA) in 2004 (Jones et $a l.)^{[28]}$ and the 10.02 years reported for Nigerian Igbo girls in 2015 (Nzeako et al.). ${ }^{[19]}$

These variations could be due to racial, geographical, nutritional and socioeconomic differences. The fact that the studies reporting an earlier mean age of pubertal onset were more recently conducted than those reporting later pubertal onset, particularly in the same countries, ${ }^{[11,25]}$ may suggest a secular trend, a decreasing average age of puberty over time, towards the earlier onset of puberty, especially in developed countries. This is attributed to better nutrition and perhaps a greater prevalence of overweight and obese girls, and improved socioeconomic conditions. In contrast, researchers in $\mathrm{SA}^{[28]}$ reported a stable onset of puberty (age of breast budding ranging 
between 9.8 - 10.5 years) for 10 - 15 years and a significant secular trend in menarche, with an average decline of 0.5 years/decade for urban black SA girls, suggesting that the tempo of pubertal maturation is increasing in girls born in the Soweto-Johannesburg area. ${ }^{[28]}$ Their finding contrasts with those of most other studies ${ }^{[1,11,23]}$ that have reported a significant secular trend in breast development and stable mean age at menarche over several decades, suggesting the end of the secular trend for menarche.

Our study did not show pubertal onset below 8 years nor above 13 years of age. All girls in B2 were interestingly within the normal documented age of pubertal onset of $8-13$ years, and therefore there was no precocious or delayed puberty in this study. This may be partly due to the small percentages of $6-8$ year olds $(4.5 \%)$ and 13 - 15 year olds (10.4\%) compared with the larger percentage of the $8-<12$ year olds $(74.5 \%)$ in the study population. The lower age of 6 years in this study population is the same as that in similar studies that reported precocious puberty, ${ }^{[6,11,26]}$ while the upper age range of 15 years in the present study was also used in similar studies (15 20 years). ${ }^{[6,11,26]}$

In this study, no girl older than 13 years was in Tanner B2. This finding could be related to the fact that none of girls in B2 was underweight. The majority were of normal weight and the minority overweight or obese. It is documented in the literature that malnutrition (undernutrition) is probably the most important mechanism responsible for delayed puberty $;^{[29]}$ therefore it is not surprising that there were no girls with delayed pubertal onset in our study.

The mean (SD) menarcheal age of 12.67 (1.65) years in this study is within the range reported in other previous studies in Nigeria, ${ }^{[18]}$ Africa ${ }^{14]}$ and developed countries. ${ }^{[6,9]}$ All the post-menarcheal girls were in B4 and B5. This buttresses the fact that menarche tended to occur toward the end of pubertal development, and therefore gives more information regarding the normal progression of puberty rather than the onset. The duration from pubertal onset to menarche of 2.17 years found in this study is similar to the 2.3 years reported by Marshall and Tanner ${ }^{[4]}$ in London, UK.

Table 3. Influence of nutrition on the age of pubertal onset

\begin{tabular}{|c|c|c|c|c|}
\hline \multirow{2}{*}{$\begin{array}{l}\text { Age of } \\
\text { pubertal } \\
\text { onset }\end{array}$} & \multicolumn{4}{|c|}{ BMI-percentile category, $n(\%)$} \\
\hline & $\begin{array}{l}\text { Normal } \\
\text { weight }\end{array}$ & Overweight* & Obese ${ }^{*}$ & Total \\
\hline $\begin{array}{l}\text { Early- } \\
\text { normal } \\
(8-10)\end{array}$ & $72(50.7)$ & $2(100)$ & $12(100)$ & $86(55.1)$ \\
\hline $\begin{array}{l}\text { Middle- } \\
\text { normal } \\
(>10-12)\end{array}$ & $54(38.0)$ & $0(0)$ & $0(0)$ & $54(34.6)$ \\
\hline $\begin{array}{l}\text { Late-normal } \\
(>12-13)\end{array}$ & $16(11.3)$ & $0(0)$ & $0(0)$ & $16(10.3)$ \\
\hline Total & ${ }^{\star} 142(100)$ & $2(100)$ & $12(100)$ & $156(100)$ \\
\hline
\end{tabular}

The finding of statistically significant increases in the mean weight, height and BMI with each progressing Tanner stage, and with menarche, is similar to the findings of Rabbani et al. ${ }^{[26]}$ and Saffari et $a l^{[11]}$ in Iran, and those of Adesina et al. ${ }^{[18]}$ in Port Harcourt, Nigeria. This suggests that the level of nutrition, commonly assessed by these anthropometric indices, plays a vital role in the onset and progression of pubertal stages. The fact that the prepubertal girls (B1) had the lowest mean weight, height and BMI and the mature girls in B5 had the highest means of these indices further supports this fact. However, it is not possible to distinguish the effect of body weight on breast development from the effect of breast development on body weight in the present cross-sectional study, since the subjects were already in a stage of breast development before measurements of weight were taken, which is a limitation. A longitudinal study would be the best approach to distinguish between the two. Rabbani et al. ${ }^{[26]}$ have shown from their study that a weight of about $30 \mathrm{~kg}$ is critical for the onset of puberty. This is similar to our results.

Even though our study population did not have precocious pubertal onset (i.e. onset before 8 years of age), the statistically significant association between overweight and obese girls with early-normal age of pubertal onset suggests that there is a relationship between overnutrition (overweight and obesity) and pubertal onset. This is similar to the findings in other studies. ${ }^{[7,10]}$ It has been hypothesised that body fat mass is a facilitator for the timing of puberty in girls. ${ }^{[30]}$ This is related to leptin levels, a hormone produced by the adipocytes, which rises in girls at the time of puberty. ${ }^{[31]}$ Overweight girls, therefore, are more likely to enter puberty at an earlier age. ${ }^{[7,8,32]}$ Our findings agree with this hypothesis. Semiz et al. ${ }^{[6]}$ however, found no statistically significant association with age of pubertal onset and weight, whether normal or overweight, while the menarcheal age of the overweight and obese was significantly lower than girls with normal weight. The reason for this disparity in findings is not quite clear, but may be related to leptin levels, which have been reported to be higher in black than white people. ${ }^{[7]}$

The finding of a statistically significant association between the Igbo ethnic group and early-normal age of pubertal onset suggests a relationship between ethnic group and age at pubertal onset, similar to other studies in the USA. ${ }^{[8,9]}$ This could be explained by a higher nutritional status of the Igbo girls, as well as other confounding factors such as socioeconomic status and probably type of diet. Furthermore, multinomial regression analysis has shown that ethnicity is not a predictor of age at onset of puberty. The finding of earlier pubertal onset in private school girls (9.90 years) compared with public school girls (11.11 years) further suggests the likely influence of socioeconomic status, which also to a large extent determines nutritional status. It is expected that girls in private schools will be of a higher socioeconomic status than those in public schools; however, the incomplete socioeconomic data obtained in the present study will not permit any conclusion on socioeconomic influence.

\section{Study limitations}

The cross-sectional study design limited the researchers from distinguishing the effect of weight on puberty from the effect of

Table 4. Influence of ethnicity on the age of pubertal onset

\begin{tabular}{lllllll}
\hline & \multicolumn{5}{c}{ Ethnic group, $\boldsymbol{n}$ (\%) } \\
\cline { 2 - 7 } Age of pubertal onset & Hausa & Fulani & Yoruba & Igbo & Others & Total \\
\hline Early-normal & $24(36.4)$ & $2(50.0)$ & $12(66.7)$ & $12(100)$ & $36(64.2)$ & $86(55.1)$ \\
Middle-normal & $30(45.5)$ & $2(50.0)$ & $6(33.3)$ & $0(0)$ & $16(28.6)$ & $54(34.6)$ \\
Late-normal & $2(18.2)$ & $0(0)$ & $0(0)$ & $0(0)$ & $4(7.1)$ & $16(10.3)$ \\
Total & $66(100)$ & $4(100)$ & $18(100)$ & $12(100)$ & $56(100)$ & $156(100)$ \\
${ }^{*}$ Fishers exact $\chi^{2}=24.184, p=0.001$. & & & & & &
\end{tabular}


puberty on weight, since the girls were already in a stage of pubertal breast development before the measurements were taken.

The incomplete socioeconomic data we encountered did not permit any conclusion on the added influence of socioeconomic status on pubertal onset.

\section{Conclusion}

The mean ages of Tanner breast stages $1-5$ and menarcheal age of girls living in Sokoto, North-West Nigeria, were within the age ranges reported worldwide. The mean age of pubertal onset demonstrated in the current study is higher than the reported age of African American girls living in the USA, but similar to white American girls living in the USA and black SA girls living in SA. Precocious and delayed puberty were not encountered. Even though the age of pubertal onset was within the normal range reported worldwide, there were variations in the age of onset within the normal range with nutrition, as the overweight or obese girls and Igbo ethnic group attained puberty in the early-normal range. It is recommended that there should be vigorous pursuit of further multicentre collaborative studies and evaluations on pubertal breast development in Nigeria and other African countries in order to validate these findings and establish normative data for the Nigerian/ African population as a whole.

Acknowledgements. The researchers are grateful to the participating schools and the girls for their co-operation, and to Dr Awosan, a consultant public health physician and statistician in UDUTH, Sokoto, for his assistance with statistics and analysis of data. We thank our research assistants, Dr Susan Adeyi and Dr Fatima Abubarkar for their help with data collection. We are grateful to Prof. Allan D Rogol, a paediatric endocrinologist, and an international tutor with the Paediatric Endocrinology Training Centre for Africa (PETCA), for critically reviewing the manuscript. Finally, we gratefully acknowledge the PETCA programme, Nairobi, Kenya, for supporting the research.

1. Dunkel L, Quinton R. Transition in endocrinology: Induction of puberty. Eur J Endocrinol 2014;170(6):229-239. http://dx.doi.org/10.1530/EJE-13-0894

2. Van den Berg SM, Setiawan A, Bartels M, et al. Individual differences in puberty onset in girls: Bayesian estimation of heritability's and genetic correlations. Behav Genet 2006;36(2): 261-70. http://dx.doi.org/10.1007/s10519-005-9022-y

3. Burt Solorzano CM, McCartney CR. Obesity and pubertal transition in girls and boys. Reproduction 2010;140(3):399-410. http://dx.doi.org/10.1530/REP-10-0119

4. Marshall WA, Tanner JM. Variations in patterns of pubertal changes in girls Arch Dis Child 1969;44(235):291-303. http://dx.doi.org/10.1136/adc. 44. 235.291

5. Khadilkar VV, Stanhope RG. Secular trends in puberty. Indian Pediatr 2006;43(17):475-478.

6. Semiz S, Kurt F, Kurt DT, Zencir M, Sevinc O. Factors affecting onset of puberty in Denizli province in Turkey. Turk J Paediatr 2009;51(1):49-55.

7. Kaplowitz PB, Slora EJ, Wasserman RC, Pedlow SE, Giddens HME. Earlier onset of puberty in girls: Relation to increased body mass index and race. Pediatrics 2001;108(2): 347-351. http://dx.doi.org/10.1542/peds.108.2.347

8. Biro FM, Greenspan LC, Galvez MP, et al. Onset of breast development in a longitudinal cohort. Pediatrics 2013;132(6):1-9. http://dx.doi.org/10.1542/ peds.2012-3773
9. Wu T, Mendola P, Buck GM. Ethnic differences in the presence of secondary sexual characteristics and menarche among US girls. The Third National Health and Nutrition Examination survey 1988-1994. Pediatrics 2002;110(4):752-757. http://dx.doi.org/10.1542/peds.110.4.752

10. Atay Z, Turan S, Guran T, Furman A, Bereket A. Puberty and influencing factors in schoolgirls living in Istanbul: End of the secular trend? Pediatrics 2011;128(1):40-45. http://dx.doi.org/10.1542/peds.2010-2267

11. Saffari F, Rostamian M, Esmailzadoha N, Shariatinjad K, Karimzadeh T. Pubertal characteristics of girls in Quazvin Province Iran. Iran J Pediatr 2012;22(3):392-398

12. Euling SY, Herman-Giddens ME, Lee PA et al. Examination of US pubertal timing data from 1940 - 1944 for secular trends: Panel findings. Pediatrics 2008;121(3):172-191. http://dx.doi.org/10.1542/peds.2007-1813D

13. Garnier D, Simondon KB, Beneface E. Longitudinal estimates of pubertal timing in Senegalese adolescent girls. Am J Hum Biol 2005;17(6):718-730. http://dx.doi. org/doi10.1002/ajhb.20435

14. Hosney LA, El-Ruby MO, Zaki ME, et al. Assessment of pubertal development in Egyptian girls. J Pediatr Endocrinol Metab 2005;18(6):577-584. https://doi. org/10.1515/JPEM.2005.18.6.577

15. Deardoff J, Molly F, Ekwaru JP, Kushi LH, Greenspan LC, Yen IH. Does neighbourhood environment influence girl's pubertal onset? Findings from a cohort study. BMC Pediatr 2012;12(1):27. http://dx.doi.org/10.1186/1471-2431$12-27$

16. Mutiagh M, Rabbani A, Kelishadi R et al. Timing of puberty in Iranian girls according to their living area - a national study. JRMS 2011;16(3):276-281.

17. Adesina AF, Peterside O. Age at menarche and body mass index (BMI) among adolescent secondary school girls in Port Harcourt, Nigeria. J Dent Med Sci 2013;3(5):41-46. https://doi.org/10.9790/0853-0354146

18. Onyiriuka AN, Egbagbe EE. Anthropometry and menarcheal status of adolescent Nigerian urban senior secondary school girls. Int J Endocrinol Metab 2013;11(2):71-75. http://dx.doi.org/10.5812/ijem.8052

19. Nzeako HC, Ezejindu DN, Iwunze AB, Obinna BN. Pubertal development in Nigerian Igbo girls. CIB Tech J Pharma 2015;4(2):45-51.

20. Country Quest. The people of Nigeria, Ethnicity. http://www.countriesquest. com/africa/nigeria/thepeopleofnigeria/ethnicity.htm (accessed 17 August 2016).

21. Kuczmarski RJ, Ogden CL, Guo SS, et al. 2000 CDC growth charts for the United States: Methods and development. Vital Health Stat 2002;11(246):31-39.

22. Charan J, Biswas T. How to calculate sample size for different study designs in Medical Research. Indian J Psychol Med 2013;35(2):121-126. http://dx.doi. org/10.4103/0253-7176.116232

23. Cabrera SM, Bright GM, Frane JW, Blethren SL, Lee PA. Age at thelarche and menarche in contemporary US females: a cross-sectional analysis. I Pediatr Endocrinol Metab 2014;27(1-2):47-51. http://dx.doi.org/10.1515/jpem.2013-0286

24. Wang Y, Chen, H. Use of percentiles and $z$-scores in anthropometry. In: Preedy VR, ed. Handbook of Anthropometry: Physical Measures of Human Form in Health and Disease. Springer Science 2012:31-33. http://dx.doi.org/10.1007/9781-4419-1788-1-2

25. Bazrafshan H, Behnampour N, Sarabandi F Mirpour S. Association between puberty and weight, height, and body mass index in a developing community JPMA 2012;62(5):454. http://dx.doi.org/10.1515/JPEM.2005.18.6.577

26. Rabbani A, Motlagh ME, Mohammed K, et al. Assessment of pubertal development in Iranian girls. Iran J Pediatr 2010;20(2):160-166.

27. Juul A, Teilmann G, Schike T, et al. Pubertal development in Danish children Comparison of recent European and US data. Int J Androl 2006;29(1):247-55. http://dx.doi.org/10.1111/j.1365-2605.2005.00556.x

28. Jones LL, Griffiths PL, Cameron N. Is puberty starting earlier in urban South Africa? Am J Hum Biol 2009;21(3):395-397. http://dx.doi.org/10.1002/ajhb.20868

29. Pozo J, Argente J. Delayed puberty in chronic illness. Best Pract Res Clin Endocrinol Metab 2002;16(1):73-90. http://dx.doi.org/10.1053/beem.2002.0182

30. Garcia-Mayor RV, Andrade MA, Rios M, et al. Serum leptin levels in normal children: Relationship to age, gender, body mass index, pituitary-gonadal hormones, and pubertal stage. J Clin Endocrinol Metab 1997;82(9):2849-55. http://dx.doi.org/10.1210/jcem.82.9.4235

31. Ahmed ML, Ong KK, Morrell DJ, et al. Longitudinal study of leptin concentrations during puberty: Sex differences and relationship to changes in body composition. J Clin Endocrinol Metab 1999;84(3):899-905. http://dx.doi. org/10.1210/jcem.84.3.5559

32. He Q, Karlberg J. BMI in childhood and its association with height gain, timing of puberty and final height. Pediatr Res 2001;49(2):244-51. http://dx.doi. org/10.1203/00006450-200102000-0001 